\title{
The influence of caffeine on the biomechanical properties of bone tissue during pregnancy in a population of rats
}

\author{
Grazyna Olchowik ${ }^{1}$, Emilia Chadaj-Polberg ${ }^{2}$, Marek Tomaszewski ${ }^{3}$, \\ Mateusz Polberg ${ }^{4}$, Monika Tomaszewska ${ }^{5}$ \\ ${ }^{1}$ Department of Biophysics, Medical University of Lublin, Poland \\ ${ }^{2}$ Department of Radiology, Police Hospital of Lublin, Poland \\ ${ }^{3}$ Department of Human Anatomy, Medical University of Lublin, Poland \\ ${ }^{4}$ Neurology Department of Regional Specialistic Hospital of Lublin, Poland \\ ${ }^{5}$ I Department of Radiology, Medical University of Lublin, Poland
}

\begin{abstract}
The influence of pregnancy on bone tissue metabolism is not completely understood. Caffeine also has a potentially negative influence on bones. The aim of this study was the evaluation of changes in the bones of pregnant rats under the influence of caffeine. The experiment was carried out on Wistar rats. The evaluation of rats' bone tissue quality was performed based on bone density measurements and resistance examinations. It analyzed the impact of caffeine on the degree of bone tissue mineralization and the composition of the bones. The mean value of pelvises 'wet' and 'dry' densities in a group of pregnant rats with caffeine intake was lower compared to the control group. The deformation in maximal load point of the femur shaft in the experimental group was significantly higher than in the control group. In the experimental group, the percentage of water in the bones was significantly higher, while the content of inorganic phase was significantly lower compared to the control group. The changes of biomechanical parameters in the group of pregnant rats with caffeine intake indicate its negative influence on the bone. Our results show higher plasticization of the bone shafts of the animals under the influence of caffeine. Higher deformation of bone shafts may have an effect on the statics of the skeleton. The administration of caffeine significantly affected the quantitative composition of the bone. (Folia Histochemica et Cytobiologica 2011; Vol. 49, No. 3, pp. 504-511)
\end{abstract}

Key words: caffeine, pregnancy, bone tissue, static mechanical properties

\section{Introduction}

The mechanical properties of bone tissue are determined by genetic and physiological factors, diet, stimulants and drugs intake as well as physical exercise. The influence of pregnancy on bone tissue metabolism is not completely understood. The developing demand for calcium in the fetus causes an increase of absorption of this element from the mother's intestines and causes bone tis-

Correspondence address: G. Olchowik,

Department of Biophysics, Medical University of Lublin,

Jaczewskiego Str. 4, 20-090 Lublin, Poland;

e-mail: grazyna.olchowik@am.lublin.pl sue turnover to increase. The rise in bone resorption starts at the beginning of the first trimester of pregnancy, while bone formation markers increase during the third trimester. During this process, redistribution of 3\% of the bone tissue takes place [1].

Caffeine also has a potentially negative influence on bone tissue. This methylxanthine is present in many food products and drugs and is widely used by pregnant women. These days, it is impossible to avoid its intake, and its effect on bone tissue is not fully understood. Researchers' opinions on the influence of caffeine on bone tissue differ.

The way in which caffeine influences the tissues of the mobility system of pregnant women still awaits 
explanation. There is no literature dealing with the impact of caffeine intake on the bone tissue of mothers during pregnancy.

The aim of this work was to evaluate changes in the bone tissue of pregnant rats exposed to caffeine. Special attention was paid to the evaluation of biomechanical parameters which determine the tensile resistance of bone.

\section{Material and methods}

The experiment was carried out on conventional outbreed albino CRL:(WI)WUBR Wistar rats obtained from a commercial breeder (Rembertow, Warsaw, Poland). The average weight of the animals was $250-270 \mathrm{~g}$.

The experiment was performed with the full approval of the University Animal Research Ethics Committee of the Medical University of Lublin, Poland.

The animals were acclimatized to the animal room for at least two weeks and handled several times before mating. The animals' room was maintained at approximately $18-25^{\circ}$ with a 12 -hour light/12-hour dark cycle (light period: 7 a.m.-7 p.m.). Municipal tap water and standard laboratory pellet rat chow $\mathrm{LSM}{ }^{\circledR}$ were provided ad libitum. After acclimatization, the virgin female rats were caged overnight with males in a 5:2 ratio. Detection of spermatozoa or a plug containing sperm and desquamated vaginal epithelium in the morning vaginal smear confirmed copulation. The day spermatozoa were found in the vaginal smear was designated as the first day of pregnancy. Animals were randomly assigned to two groups: experimental (E) and control (C), with eight rats in each group.

Caffeine of $99 \%$ purity (caffeine anhydrous powder, Sigma - Aldrich Chemie GmbH, Germany) was used in the experiment. The caffeine was administered at $25^{\circ} \mathrm{C}$ intragastrically at a dose of $30 \mathrm{mg} /$ day to the female from the experimental group (E), once daily, from the eighth until the $21^{\text {st }}$ day of pregnancy. Females in the control group (K) received water of the same temperature and volume as those given in the experimental group.

Body mass was controlled at three day intervals. On the $21^{\text {st }}$ day of the experiment, each dam was sacrificed by decapitation using a specially adapted laboratory guillotine. Death was caused by interruption of the spinal cord without interruption of the integument. The femurs and pelvises were dissected and cleaned of soft tissue. The samples prepared for biomechanical examinations were stored at $-15^{\circ} \mathrm{C}$.

The evaluation of rats' bone tissue quality in experimental and control groups was performed based on the measurement of bone density and biomechanical tests.

The mean density of bones (d) was evaluated. It was defined as a mass of the whole bone with epiphyses and physiological fluids inside to its volume ratio. The bone volume was defined using the hydrostatic method. Bone 'dry' density $\left(\mathrm{d}_{\mathrm{s}}\right)$ is defined after the removal of water from bone and may indicate the structural changes of the bone [2]. It was defined as the weight of the bone dried in $105^{\circ} \mathrm{C}$ temperature for 24 hours to its volume ratio.

The mechanical tests of femurs were performed using a testing machine (Lloyd, type LRX). Bones aimed at resistance tests were stored at $-15^{\circ} \mathrm{C}$. Before the tests, femurs were defrosted at room temperature for 12 hours. Until the implementation of biomechanical tests, the bones were stored in $0.9 \% \mathrm{NaCl}$. Then samples were placed in a specially constructed holder and exposed to a cross load with $2 \mathrm{~mm} /$ minute speed, which caused the break.

Biomechanical parameters were determined on the basis of characteristics received in a three point test. The distance between end supports of the testing apparatus was $2 \mathrm{~cm}$. Typical course of curve of load [N] applied to the middle part of bone shaft to head shift dependence is presented in Figure 1. The value of the force was registered on the axis of ordinates and the movement of the head of measuring apparatus on the axis of abscissas. Based on the resistance characteristics, the maximal load $\left(\mathrm{F}_{\text {max }}\right)$ and deformation $\left(\delta_{\max }\right)$ were determined. Stiffness of the bone shaft $(\mathrm{H})$ was determined as tangent of slope angle of rectilinear section of resistance characteristic $[2,3]$.

The strain in the point of the maximal load $\left(\mathrm{N}_{\max }\right)$ was counted from the dependence (1) [3]:

$$
\mathrm{N}_{\max }=\frac{\mathrm{F}_{\max } \mathrm{Lr}_{1 \max }}{4 \mathrm{I}}
$$

where:

$\mathrm{L}$ - distance between points of bone shaft support;

$\mathrm{r}_{1 \max }$ - largest radius;

I - area moment of inertia;

$$
\mathrm{I}=\frac{\left(\mathrm{r}_{1 \min } \times \mathrm{r}_{1 \max }{ }^{3}\right)-\left(\mathrm{r}_{2 \min } \times \mathrm{r}_{2 \max }{ }^{3}\right)}{\frac{\pi}{4}}
$$

where:

I - area moment of interia;

$\mathrm{r}_{1 \min }-$ minimum outside radius;

$\mathrm{r}_{1 \max }$ - maximum outside radius;

$\mathrm{r}_{2 \min }-$ minimum inside radius;

$\mathrm{r}_{2 \max }-$ maximum inside radius.

We also analyzed the degree of the force in the border of elasticity $\left(\mathrm{F}_{\mathrm{p}}\right)$; the deformation caused by its action $\left(\delta_{\mathrm{p}}\right)$ and tension in bone $\left(\mathrm{N}_{\mathrm{p}}\right)$.

The strain in the border of elasticity was counted from the dependence (3):

$$
\mathrm{N}_{\mathrm{p}}=\frac{\mathrm{F}_{\mathrm{p}} \mathrm{Lr}_{1 \max }}{4 \mathrm{I}}
$$

Our study also analyzed the impact of caffeine on the degree of bone tissue mineralization and the composition of the bones of pregnant rats (water content, organic and inorganic phases). For this purpose, bone mass with epi- 


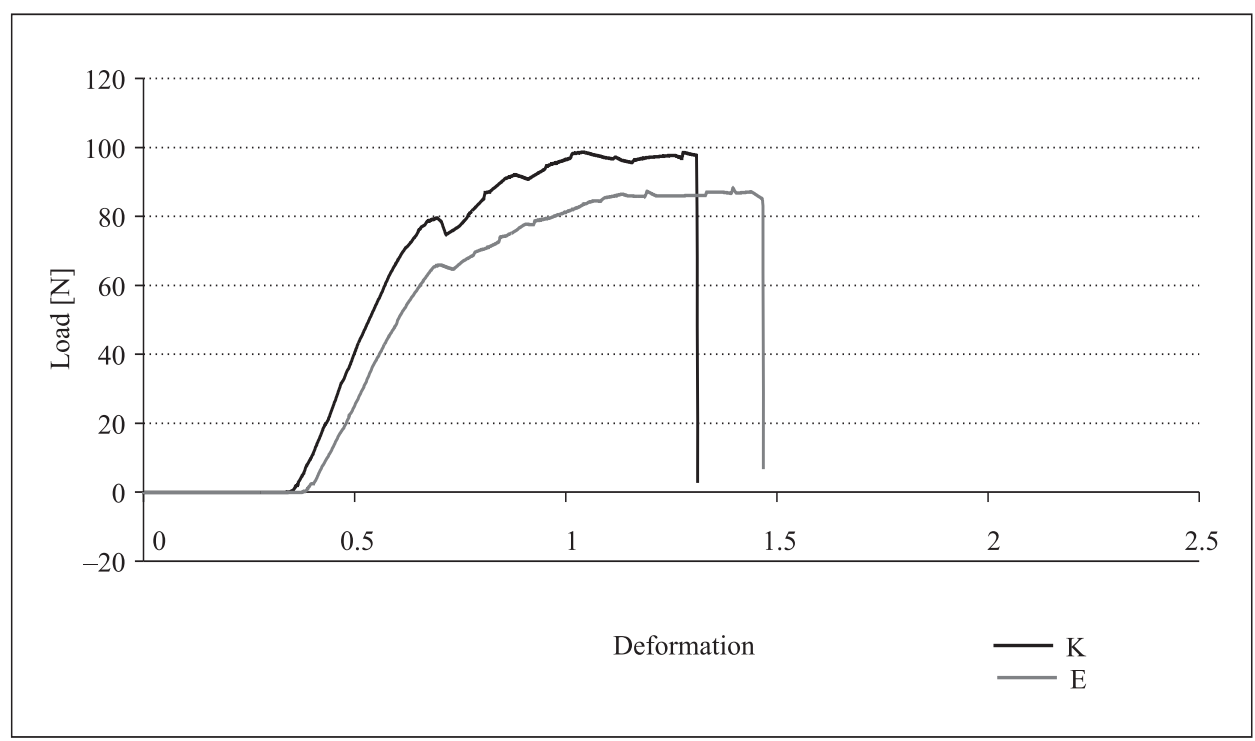

Figure 1. Typical load-deformation in the femur shaft bending three point test in the groups of animals; $\mathrm{K}-$ control group; E - pregnant females with caffeine applied

physes and contained within the physiological fluids $\left(\mathrm{m}_{1}\right)$ was assessed, then the mass of the dry bone $\left(\mathrm{m}_{\mathrm{s}}\right)$. The dry bone mass was determined after drying the sample of bone at $105^{\circ} \mathrm{C}$ for $24 \mathrm{~h}$. For the determination of the organic and mineral phases, bone samples were ashed in a muffle furnace at a temperature of $630^{\circ} \mathrm{C}$ for 24 hours, and then incinerated samples were weighed $\left(\mathrm{m}_{\mathrm{a}}\right)$.

The percentage of water $(\mathrm{W})$, the organic phase $(\mathrm{O})$ and mineral phase (A) in samples were determined according to dependence [4]:

$$
\begin{gathered}
\mathrm{W} \%=100 \frac{\mathrm{m}_{1}-\mathrm{m}_{\mathrm{s}}}{\mathrm{m}_{1}}(4) \\
\mathrm{Org} \%=100 \frac{\mathrm{m}_{\mathrm{s}}-\mathrm{m}_{\mathrm{a}}}{\mathrm{m}_{1}}(5) \\
\mathrm{A} \%=100 \frac{\mathrm{m}_{\mathrm{a}}}{\mathrm{m}_{1}}(6)
\end{gathered}
$$

The degree of mineralization of organic matrix $(\mathrm{M})$ was calculated according to the dependence [4]:

$$
\mathrm{M} \%=100 \frac{\mathrm{m}_{\mathrm{a}}}{\mathrm{m}_{\mathrm{s}}}(7)
$$

The results were given as means and standard deviations. The significance analysis of the differences between groups was performed using the $t$-test. Significance between groups was accepted at a level of $\mathrm{p}<0.05$.

\section{Results}

The mean initial body mass and the body mass at the end of the experiment did not differ significantly between the control and experimental group. The mean body weight gain between both groups of animals is shown in Figure 2.
The mean 'wet' (d) and 'dry' (ds) bone densities in both groups of animals are shown in Table 1 . The significantly higher value of bone 'wet' density ( $p=$ $=0.0013)$ and bone 'dry' density $(p=0.0015)$ were noticed in the group of pregnant females which received water (Group K). The caffeine significantly influenced the bone density, causing it to decrease.

The biomechanical parameters determined at the point of maximal load are shown in Table 1. The value of the force that breaks the femur shaft $\left(\mathrm{F}_{\max }\right)$ was higher in the group of pregnant rats without the caffeine intake $(\mathrm{K})$ than in the group with administered caffeine (E). However, the difference was not significant. The bending to the maximal load point of the femur shaft $\left(\delta_{\max }\right)$ in Group E was marginally higher than in the control group $(\mathrm{p}=0.0587)$. In the group of animals with administered caffeine, internal tensions in femur shafts undergoing deformation until maximal load point $\left(\mathrm{N}_{\max }\right)$ were lower than in the control group $(\mathrm{K})$, although the differences were not significant.

The conducted examinations showed that caffeine significantly $(\mathrm{p}=0.0073)$ decreased the hardness $(\mathrm{H})$ of the pregnant females' bones, compared to the control group (Table 1).

Important for the evaluation of mechanical properties of bones are the parameters determined through the examination of the range of loads that cause elastic deformation. Mean values of the measured and calculated biomechanical parameters at the onset of elasticity in both groups of animals are shown in Table 1.

There were no significant differences in the value of the force determined at the border of elasticity $\left(\mathrm{F}_{\mathrm{p}}\right)$ between the control and experimental group. Significant changes were noticed in the range of deformities of the femur shafts $\left(\delta_{\mathrm{p}}\right)$ at the border of elasticity. The value of 


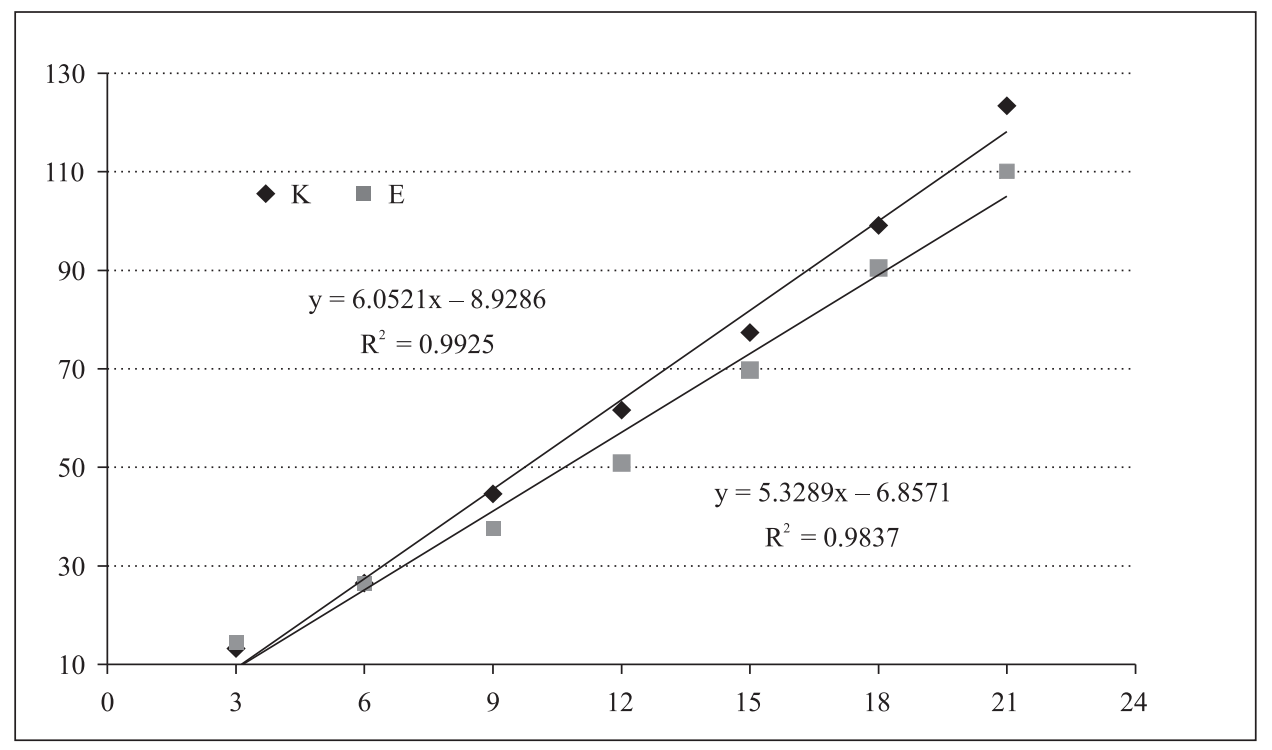

Figure 2. The body mass increase of pregnant rat females with caffeine (E) and water (K) applied in dependence of pregnancy duration

Table 1. The results in groups of animals

\begin{tabular}{|c|c|c|c|c|c|}
\hline \multirow[t]{2}{*}{ Parameter } & \multicolumn{2}{|c|}{$\mathbf{K}$} & \multicolumn{2}{|c|}{ E } & \multirow[t]{2}{*}{$\mathbf{p}$} \\
\hline & Mean & $\pm \mathrm{SD}$ & Mean & $\pm \mathrm{SD}$ & \\
\hline$\Delta \mathrm{m}[\mathrm{mg}]$ & 123.36 & 14.85 & 110.13 & 22.99 & 0.1926 \\
\hline $\mathrm{d}\left[\mathrm{kg} / \mathrm{m}^{3}\right]$ & 1500.29 & 11.39 & 1467.22 & 20.34 & 0.0013 \\
\hline $\mathrm{d}_{\mathrm{s}}\left[\mathrm{kg} / \mathrm{m}^{3}\right]$ & 915.94 & 21.40 & 861.03 & 33.04 & 0.0015 \\
\hline $\mathrm{F}_{\max }[\mathrm{N}]$ & 97.20 & 8.95 & 95.49 & 7.12 & 0.67891 \\
\hline$\delta_{\max }$ & 0.23 & 0.01 & 0.26 & 0.04 & 0.0587 \\
\hline $\mathrm{N}_{\max }[\mathrm{MPa}]$ & 5.05 & 0.77 & 4.66 & 0.46 & 0.2390 \\
\hline $\mathrm{H}[\mathrm{N} / \mathrm{mm}]$ & 262.99 & 20.31 & 234.06 & 16.42 & 0.0073 \\
\hline $\mathrm{F}_{\mathrm{p}}[\mathrm{N}]$ & 67.57 & 1.61 & 68.28 & 6.42 & 0.7664 \\
\hline$\delta_{\mathrm{p}}$ & 0.049 & 0.005 & 0.056 & 0.005 & 0.0135 \\
\hline $\mathrm{N}_{\mathrm{p}}[\mathrm{MPa}]$ & 4.07 & 0.64 & 3.71 & 0.40 & 0.1987 \\
\hline $1[\mathrm{~mm}]$ & 34.26 & 0.51 & 34.74 & 0.87 & $>0.8$ \\
\hline $\mathrm{s}\left[\mathrm{mm}^{2}\right]$ & 6.46 & 0.54 & 6.04 & 0.55 & 0.1456 \\
\hline $\mathrm{W}(\%)$ & 38.91 & 1.18 & 41.33 & 1.64 & 0.0425 \\
\hline $\mathrm{O}(\%)$ & 20.83 & 0.16 & 20.71 & 0.82 & $>0.8$ \\
\hline $\mathrm{A}(\%)$ & 40.26 & 1.12 & 37.96 & 1.27 & 0.0079 \\
\hline $\mathrm{M}(\%)$ & 65.84 & 0.43 & 64.69 & 1.03 & 0.1382 \\
\hline
\end{tabular}

$\mathrm{K}$ - control group; $\mathrm{E}$ - pregnant females with caffeine applied; $\Delta \mathrm{m}$ - increase of body mass in dependence of time; $\mathrm{d}$ - density of pelvic bones; $\mathrm{d}_{\mathrm{s}}-$ 'dry' density of pelvic bones; $\mathrm{F}_{\max }$ - maximum load that breaks the femoral shaft; $\delta_{\max }$ - deformation of femoral shaft to the maximal load point; $\mathrm{N}_{\max }$ - strain of femoral shaft in the maximal load point; $\mathrm{H}$ - stiffness of femoral shaft; $\mathrm{F}_{\mathrm{p}}$ — yield load of femoral shaft;

$\delta \mathrm{p}$ - deformation of femoral shaft to the border of elasticity; $\mathrm{N}_{\mathrm{p}}$ - strain of femoral shaft in the border of elasticity; $\mathrm{L}$ - length of femur; $\mathrm{s}$ - cross-section field of femoral shaft cortex in the break zone; $\mathrm{W}$ - water content in the bone; $\mathrm{O}$ - organic phase content in the bone;

A - mineral phase content in the bone; $\mathrm{M}$ - degree of mineralization of the organic matrix of the bone

tension in the femur shaft $\left(\mathrm{N}_{\mathrm{p}}\right)$ calculated at the border of elasticity in the group subjected to the influence of caffeine was lower than in the control group $\mathrm{K}$, although the difference was not statistically significant.
The results of water, organic and inorganic phases content in the bone matrix and the degree of mineralization of organic matter in different groups of animals are presented in Table 1 . In the group of fe- 
males exposed to caffeine, the percentage of water in the bones was significantly higher compared to the control group. Average percentage of organic phase in bone did not differ significantly between groups of animals. The content of inorganic phase was significantly lower in the animals from the experimental group compared to the control group. Caffeine did not affect significantly the degree of mineralization of organic matrix.

\section{Discussion}

Density of the bone tissue is one of the basic parameters which determine its quality and susceptibility to fractures. The conducted experiment showed that caffeine influenced bone density in pregnant rats. The mean value of the density of the pelvis in the group of pregnant rats under the influence of caffeine (E) was $2.20 \%$ lower compared to the control group $(\mathrm{K})$. Similar changes were observed in the 'dry' density of the bones, which was $5.99 \%$ lower in the group under the influence of caffeine than in the control group (Table 1).

Data concerning the bone density does not exhaust the full range of information allowing the determination of the risk of fractures. Mechanical resistance of bones is more likely to be determined on the basis of the examination of resistance in isolated and untouched bones [5].

Obtained values of biomechanical parameters determined at the maximal load point showed the negative influence of caffeine on the bone tissue of pregnant rats. While it is true that the significant changes between both groups of rats were not noticed in the values of force that breaks the femur shaft, the bones bent $12.55 \%$ more before reaching the point of maximal load in the group with caffeine intake.

Similar character of changes was observed in the values determined at the maximum stress point (Table 1). There was a decrease of stress values of $7.72 \%$ in the group of pregnant females with caffeine intake compared to the pregnant control group. Significant changes were observed in bone stiffness between both groups of animals. Bone stiffness of pregnant females with caffeine intake was about $11 \%$ lower compared to the control group (K).

The changes of biomechanical parameters in the group of pregnant females with caffeine intake indicate its negative influence on the bone tissue of pregnant females. Differences in investigated parameters between the groups were significant.

The mechanical properties of bone, its resistance and elasticity are determined, among other things, by its microarchitecture (thickness and location of the bone trabecules) and geometry, shape, size, and, above all, thickness of the cortical zone. As a result of the operation of deforming forces, breaking begins on the external surface of the long bone shaft. In consequence, the structure which determines resistance to fracture is the cortical zone of the bone. Since there were no significant differences in the geometric dimensions of the examined bones (Table 1), so the observed changes in biomechanical parameters were probably a consequence of structural changes in the bone tissue.

Of major importance for the evaluation of mechanical properties of bones are the parameters determined in the range of loads causing the elastic deformation. Elastic deformations of bones are reversible. This means that they recede as soon as the mechanical load is removed. Parameters determined at the border of elasticity have significant importance in the determination of the quality of bone tissue, because during everyday physical activity tensions that occur in the bone tissue do not reach the border of elasticity. Beyond this point, bone yields to permanent deformation, which may be the result of multiplied microfractures in the bone.

Performed mechanical tests did not show significant differences in the values of the load that causes the deformation of the femur shafts to the border of elasticity (Table 1). However, the bones of animals under the influence of caffeine deformed more, and those changes were statistically significant. Deformation of the femur shaft to the border of elasticity in the group of pregnant females which had been receiving caffeine was $16.66 \%$ higher than in the control group. In addition, the values of the tensions that reflect the range of elastic deformations of the femur shafts were lower in the group that received the caffeine. However, these changes were not statistically significant.

According to the data obtained in this experiment, differences in values of biomechanical parameters between groups of animals were reflected in the composition of the bone. The bones of pregnant rats exposed to caffeine showed $2.42 \%$ higher water content and $2.30 \%$ lower mineral phase content compared to the control group. There were no significant changes in the mineralization of organic matrix.

Obtained results show higher plasticization of the bone shafts of the animals under the influence of caffeine. Higher deformation of bone shafts may have an effect on the statics of the skeleton.

It should be stressed that in the conducted experiment high doses of caffeine were used i.e. $30 \mathrm{mg}$ per $300 \mathrm{~g}$ of body mass (this corresponds to $100 \mathrm{mg} / \mathrm{kg}$ b.m). The median lethal dose (LD50) of caffeine 
administered orally to rats is $192 \mathrm{mg} / \mathrm{kg} \mathrm{b}$.m. The maximum dose of the caffeine administered orally to humans is $1.5 \mathrm{~g}$, while the lethal dose is $10-12$ grams of caffeine, which corresponds to $150 \mathrm{mg} / \mathrm{kg}$ b.m. In fact, in the literature there are reports of lethal intoxication after ingestion of $500 \mathrm{mg}$ of this methylxanthine. On the other hand, there are also descriptions of survival of a patient who received a caffeine intake of $24 \mathrm{~g}[6,7]$.

To the best of our knowledge, there have been no reports in the world literature about the influence of caffeine on the bone tissue of pregnant females. There are only studies investigating the influence of caffeine on the bone tissue of females, especially in the perimenopause period.

There are attempts to understand the molecular mechanism of caffeine influence on bones. 1,25-Dihydroxyvitamin $\mathrm{D} 3\left(1,25(\mathrm{OH})_{2} \mathrm{D}_{3}\right)$ performs a fundamental role in the regulation of bone metabolism. A receptor for this vitamin (VDR, Vitamin D Receptor) occurs in osteoblast cells. This means that a high caffeine dose may influence VDR expression stimulated by vitamin $1,25(\mathrm{OH})_{2} \mathrm{D}_{3}$ and controlled by vitamin $1,25(\mathrm{OH})_{2} \mathrm{D}_{3}$ activity of human osteoblast cells by reducing alkaline phosphatase activity [8].

The impact of caffeine on bone tissue is related to calcium metabolism. Caffeine slightly impairs calcium absorption from intestines; however it has no effect on calcium excretion with urine. Still its intake causes a decrease of bone mass and an increase of bone fracture risk. Caffeine has no destructive influence on the bone tissue of people with sufficient calcium intake [9]. It has been proved that a high caffeine intake ( $>450 \mathrm{mg} /$ day) by women in the perimenopausal period causes increased loss of mineral density in bones; however this is only in cases of low calcium intake (below $800 \mathrm{mg} /$ day). The study [10] stated that caffeine caused increased calcium excretion with urine, but there was no relation to mineral density of the bone tissue.

Some authors [10-13] did not observe a relation between caffeine intake and bone tissue loss in women after menopause. Reid et al. [14] claimed that the most important factors that influence bone tissue loss in women after menopause are: peak bone mass, quantity of fat and calcium excretion in kidneys. The amount of caffeine intake has no influence on bone tissue.

Other researchers [15] investigated the influence of caffeine taken in doses of $100 \mathrm{mg} / \mathrm{d}$ on the bone tissue of young women. They measured BMD (Bone Mineral Density) of the lumbar vertebral column and the femoral neck in women aged between 19 and 26. BMD decreases of about $0.0069 \mathrm{~g} / \mathrm{cm}^{2}$ in the femoral neck and about $0.0119 \mathrm{~g} / \mathrm{cm}^{2}$ in the lumbar vertebral column were observed.

A caffeine intake over a period of six years at a dose of $400 \mathrm{mg} / \mathrm{d}$ by women aged 50-59 was connected to an elevated risk of fractures after menopause [16]. Women aged 40-49 who drank more than nine cups of coffee per day with a small intake of calcium had a higher risk of fractures. Caffeine was a risk factor for osteoporotic fracture development [17].

High doses (more than $300 \mathrm{mg} / \mathrm{d}$ ) of methylxanthine caused a drop in BMD in the trochanter and the femoral neck and in the lumbar spine among elderly women (aged 65-77). The level of serum osteocalcin was increased. A particular genetic variant of VDR had an influence on bone tissue [18].

Other authors [19] showed the positive influence of oral contraceptives on bone tissue of women aged 20-29 with $90 \mathrm{mg} / \mathrm{d}$ caffeine intake. This protective effect was most likely caused by the reduction of the most active metabolite of caffeine - paraxanthine in the kidneys.

One study [10] showed that caffeine taken in $<25 \mathrm{mg} / \mathrm{d}, 25-50 \mathrm{mg} / \mathrm{d}$ and $>50 \mathrm{mg} / \mathrm{d}$ doses by $12-$ -18 year-old girls did not cause changes in mineral bone density. The values of BMD and BMC (Bone Mineral Content) did not differ between groups of girls with and without caffeine intake.

Caffeine administered to ovariectomized rats on the $90^{\text {th }}$ day of their life at a dose of $20 \mathrm{mg} / \mathrm{kg}$ caused a significant decrease of biomechanical parameters of femurs such as maximal load, load to elasticity limit, maximal stress, and deformation to maximal loadpoint. Elasticity module did not change [20].

It has been proved that caffeine applied at a dose of $40 \mathrm{mg} / \mathrm{kg}$ to young rat females after ovariectomy on the $32^{\text {nd }}$ day of life caused mineral loss in the bones and weakening of mechanical properties such as maximal load to the border of elasticity [21].

One study [22] confirmed the negative influence of caffeine on osteoblast cells of rats. It was proved that caffeine caused changes in their vitality and increased their apoptosis rate.

Pregnancy itself may have a negative influence on bone tissue. Some authors [23-25] have observed significant changes in the bones, especially in the areas rich in the trabecular bone, in pregnant females. Researchers measured BMD by using dual-energy X-ray absorptiometry (DEXA).

Kaur et al. [23] measured BMD in 46 women before conception and then immediately after delivery. They found that during pregnancy there was a significant decrease in BMD by $4.2 \%$ at the trochanter. In other areas of the skeleton, the losses were about $1 \%$. 
Ulrich et al. [24] examined BMD before conception and two weeks after parturition in 15 women. They showed a significant decrease in BMD by $3.4 \pm$ $\pm 4.1 \%$ in the lumbar spine $(3.4 \%)$ and by $4.3 \pm 3.9 \%$ in the trochanter, while it was noticed that there occurred a significant increase in BMD at the proximal third of the forearm $(1.3 \pm 1.9 \%)$. In addition, the authors observed a significant increase in bone resorption markers ( $\mathrm{N}$-terminal crosslinked telopeptide of the alpha chain of type I collagen, C-terminal crosslinked telopeptide of the alpha chain of collagen type I) and a reduction of alkaline phosphatase (first trimester) and osteocalcin (second trimester).

The negative influence of pregnancy on bone tissue was also shown by Namgung and Tsuang [25]. They concluded that in the first trimester bone resorption markers increase, while bone formation markers increase in the last trimester. Postpartum BMD was reduced by $3.5 \%$ within the spine region.

The influence of pregnancy on the bone tissue has also been confirmed by experimental studies [26]. The study consisted in the measurement of biomechanical markers of bone turnover and BMD of femur and tibia in rats during pregnancy and lactation periods. The beginning of pregnancy was associated with a significant increase in serum total alkaline phosphatase and osteocalcin levels, but serum calcium, urine calcium/creatinine ratio or the BMD of long bones were not significantly different from that at the proestrus stage of the estrous cycle. A significant decrease in the BMD of the femur was observed on days 5 and 21 of lactation compared to that during pregnancy or the estrous cycle.

Vajda et al. [27] compared changes in cortical and cancellous bone mass, structure, and dynamics with mechanical properties during and after the first reproductive cycle in rats. Measurements were taken in the femoral cortical bone and lumbar vertebral body cancellous bone. The authors concluded that at the end of pregnancy, there was an increase in cortical periosteal bone formation and an increase in cortical volume. In cancellous bone, they found suppression of turnover, although the mechanical properties of cortical and cancellous bone did not change after pregnancy.

Honda et al. [28] analyzed changes in the structure and metabolism of trabecular bone and marrow adipocytes in rats during pregnancy and postpartum by assessing BMD and bone and fat histomorphometrically. They concluded that a significant decrease occurred in the trabecular bone at the end of pregnancy and during lactation. A significant reduction in the percentage of volume and number of adipocytes occurred during postpartum, and showed a negative correlation with the osteoid volume values.

\section{Conclusions}

The results of bone density and biomechanical parameters measurement obtained in this study shows that caffeine intake during pregnancy has a negative influence on the bone tissue of rat females. It caused their weakening under mechanical loads. The obtained results suggest that caffeine intake during pregnancy causes bone tissue loss.

\section{Acknowledgement}

Authors thank to Prof. Franciszek Burdan for his help in preparation of this work.

\section{References}

1. Oliveri B, Parisi MS, Zeni S, Mautalen C. Mineral and bone mass changes during pregnancy and lactation. Nutrition. 2004;20:235-240.

2. Martin RB. Effects of stimulated weightlessness on bone properties in rats. J Biomech. 1990;23:1021-1029.

3. Kaneps AJ, Stover SM, Lane NE. Changes in canine cortical and cancellous bone mechanical properties following immobilization and remobilization with exercise. Bone. 1997;21: 419-423.

4. Martin RB. Effects of stimulated weightlessness on bone properties in rats. J Biomech. 1990;23:1021-1029.

5. Filip R. Własności strukturalne i materiałowe tkanki kostnej a ryzyko złamań. Reumatologia. 2007;47:154-157.

6. Kerrigan S, Lindsey T. Fatal caffeine overdose: two case reports. Forensic Sci Int. 2005;153:67-69.

7. Nawrot P, Jordan S, Eastwood J, Rotstein A, Hugenholtz A, Feeley M. Effects of caffeine on human health. Food Addit Contam. 2003;20:1-30.

8. Rapuri PB, Gallagher JC, Nawaz Z. Caffeine decreases vitamin D receptor protein expression and $1,25(\mathrm{OH})_{2} \mathrm{D}_{3}$ stimulated alkaline phosphatase activity in human osteoblast cells. J Steroid Biochem Mol Biol. 2007;103:368-371.

9. Heaney RP. Effects of caffeine on bone and the calcium economy. Food Chem Toxicol. 2002;40:1263-1270.

10. Lloyd T, Johnson-Rollings N, Eggli D, Kieselhorst K, Mauger EA. Dietary caffeine intake is not correlated with adolescent bone gain. J Am Coll Nutr. 1998;17:454-457.

11. Grainge MJ, Coupland CAC, Cliffe SJ, Chilvers CED, Hosking DJ. Nottingham EPIC Study Group. Cigarette smoking, alcohol and caffeine consumption, and bone mineral density in postmenopausal women. Osteoporosis Int. 1998;8:355-363.

12. Lloyd T, Johnson-Rollings N, Kieselhorst K, Eggli D, Mauger EA. Dietary caffeine intake and bone status of postmenopausal women. Am J Clin Nutr. 1997;65: 1826-1830.

13. Rico H, Canal ML, Mańas P, Lavado JM, Costa C, Pedrera JD. Effects of caffeine, vitamin D, and other nutrients on quantitive phalangeal bone ultrasound in postmenopausal women. Nutrition. 2002;18:189-193.

14. Reid IR, Ames RW, Evans MC, Sharpe SS, Gamble DG. Determinants of the rate of bone loss in normal postmenopausal women. J Clin Endocrinol Metab. 1994;79:950-954.

15. Conlisk JA, Galuska AD. Is caffeine associated with bone mineral density in young adult women? Prev Med. 2000; 31:562-568. 
16. Hernandez-Avila M, Coldits GA, Stampfer MJ, Rosner B, Speizer F, Willett WC. Caffeine, moderate alcohol intake, and risk of fractures of the hip and forearm in middle-aged women. Am J Clin Nutr. 1991;54:157-163.

17. Meyer HE, Pedersen JI, Løken EB, Tverdal A. Dietary factors and the incidence of hip fracture in middle-aged Norwegians. A prospective study. Am J Epidemiol. 1997;145: 117-123.

18. Rapuri PB, Gallagher JC, Kinyamu HK, Ryschon KL. Caffeine intake increases the rate of bone loss in elderly women and interacts with vitamin D receptor genotypes. Am J Clin Nutr. 2001;74:694-700.

19. Ribeiro-Alves MA, Trugo LC, Donangelo CM. Use of oral contraceptives blunts the calciuretic effect of caffeine in young adult women. $J$ Nutr. 2003;133:393-398.

20. Ohta M, Cheuk G, Thomas KA et al. Effects of caffeine on the bones of aged, ovariectomized rats. Ann Nutr Metab. 1999;43:52-59.

21. Ohta M, Ide K, Cheuk $\mathrm{G}$ et al. A caffeine diet can alter mechanical properties of the bones of young ovariectomized rats. Ann Nutr Metab. 2002;46:108-113.

22. Tsuang YH, Sun JS, Chen LT, Sun SCK, Chen SC. Direct effects of caffeine on osteoblastic cells metabolism: the pos- sible casual effect of caffeine on the formation of osteoporosis. J Orthop Surg 2006. [online]: www.josr-online.com/content $/ 1 / 1 / 7$

23. Kaur M, Pearson D, Godber I, Lawson N, Baker P, Hosking D. Longitudinal changes in bone mineral density during normal pregnancy. Bone. 2003;32:449-454.

24. Urlich U, Miller PB, Eyre DR, Chesnut CH, Schleubusch H, Soules MR. Bone remodeling and bone mineral density during pregnancy. Arch Gynecol Obstet. 2003;268:309-316.

25. Namgung R, Tsuang RC. Bone in the pregnant mother and newborn at birth. Clinica Chimica Acta. 2003;333:1-11.

26. Sengupta S, Arshad M, Sharma S, Dubey M, Singh MM. Attainment of peak bone mass and bone turnover rate in relation to estrous cycle, pregnancy and lactation in colony-bred Sprague-Dawley rats: suitability for studies on pathophysiology of bone and therapeutic measures for its management. J Steroid Biochem Mol Biol. 2005;94:421-429.

27. Vajda EG, Bowman BM, Miller SC. Cancellous and cortical bone mechanical properties and tissue dynamics during pregnancy, lactation and postlactation in the rat. Biol Reprod. 2001;65:689-695.

28. Honda A, Kurabayashi T, Yahata T et al. Effects of pregnancy and lactation on trabecular bone marrow adipocytes in rats. Calcif Tissue Int. 2000;67:367-372.

Submitted: 24 October, 2010 Accepted after reviews: 3 April, 2011 